\title{
Pembinaan Keagamaan dan Transformasi Keilmuan di Dabatan Kabupaten Raja Ampat
}

\author{
Nurfadila Loji \\ Lodjifadila2020@gmail.com \\ Institut Agama Islam Negeri Sorong \\ Muhammad Satir \\ msatiriainsorong@gmail.com \\ Institut Agama Islam Negeri Sorong
}

\begin{abstract}
Abstrak: Pembinaan keagamaan dan transformasi keilmuah di Dabatan, Raja Ampat merupakan kegiatan pendampingan yang dilakukan oleh mahasiswa STAIN Sorong yang bertujuan untuk memberikan penyuluhan keagamaan dan pendidikan sehingga masyarakat dapat memahami agamanya dengan baik dan taraf pendidikannya megnalami peningkatan. Sebelum melakukan pendampingan, penulis melakukan wawancara terkait problematika yang dihadapi oleh masyarakat dalam bidang keagamaan dan pendidikan. Setelah menemukan titik masalah, penulis lalu melakukan pendampingan dan pembinaan untuk mengatasi problematika yang dihadapi oleh masayarakat. Pendampingan ini melibatkan banyak unsur, termasuk anak-anak yang terlibat dalam pendampingan dalam bidang pendidikan.
\end{abstract}

Kata Kunci: Transformasi, Pendampingan, Dabatan 


\section{A. PENDAHULUAN}

Kegiatan Kuliah Kerja Nyata (KKN) merupakan salah satu bentuk kegiatan yang memberikan pengalaman belajar kepada mahasiswa untuk hidup di tengah-tengah masyarakat di luar kampus. Sekaligus sebagai proses pembelajaran serta mengabdi kepada masyarakat yang sedang membangun dan secara langsung mengidentifikasi serta menangani masalah-masalah pembangunan yang sedang dihadapi. KKN dilaksanakan oleh perguruan tinggi dalam upaya meningkatkan misi dan bobot pendidikan pada mahasiswa untuk mendapat nilai tambah yang lebih besar pada pendidikan tinggi, sekaligus merupakan bagian integral kurikulum di STAIN Sorong yang tidak dapat dipisahkan dari proses pembelajaran untuk mencapai tujuan pendidikan.

Kuliah Kerja Nyata (KKN) dilaksanakan pada masyarakat di luar kampus dengan maksud meningkatakan relevansi pendidikan tinggi dengan perkembangan dan kebutuhan masyarakat akan ilmu pengetahuan. Teknologi agama serta seni untuk melaksanakan pembangunan yang semakin meningkat serta meningkatkan persepsi mahasiswa tentang relevansi antara landasan teori yang diperoleh di bangku perkuliahan untuk diaplikasikan dalam kehidupan masyarakat secara nyata.

Bagi mahasiswa, kegiatan KKN merupakan pengalaman belajar baru yang tidak diperoleh didalam kampus. Dengan selesainya KKN mahasiswa memiliki pengetahuan, kemampuan, dan kesadaran baru tentang bermasyarakat, berbangsa dan bernegara. Kuliah Kerja Nyata (KKN) merupakan suatu bentuk aktivitas perkuliahan intrakurikuler dengan desain tertentu yang bersifat praktis sebagai salah satu langkah pendidikan keterampilan dan sub-sistem proses pemberdayaan untuk mencapai tujuan pendidikan yang telah ditentukan.

Sebagai proses pembelajaran, maka spesifik kegiatan KKN ini adalah terintregasinya ketiga pilar dari Tri Dharma perguruan tinggi yang meliputi unsur-unsur dasar pendidikan dan pelatihan keterampilan keberagaman pengembangan kampus, pengabdian kepada masyarakat dan pemenuhan angka kredit kuliah. Dilihat dari substansi kegiatan, KKN memiliki dua makna: 
Pertama makna pengabdian, KKN diartikan sebagai proses untuk mengenal persoalan yang ada di tengah-tengah masyarakat. Dalam konteks ini peserta KKN diharapkan mempunyai kemampuan untuk menggali data yang berkaitan dengan masalah individu atau kelembagaan yang diderita oleh masyarakat.

Kedua, KKN diartikan sebagai keilmuan (pembelajaran). KKN merupakan proses untuk mengembangkan, menguji, dan menemukan teori yang diambil realitas atau fenomena yang terjadi di tengah-tengah masyarakat. Konsekuensinya, peserta KKN harus memiliki kemampuan untuk melakukan observasi, mengumpulkan data, memahami dan menganalisis serta menyimpulkan data dan fakta yang ada pada warga masyarakat.

Pelaksanaan kegiatan Kuliah Kerja Nyata (KKN) STAIN Sorong bertitik tolak pada landasan pemikiran bahwa STAIN merupakan bagian yang tidak dapat dipisahkan dari masyarakat. Sejalan dengan dinamika kemajuan masyarakat dan perubahan-perubahan dalam pembangunan, maka pelaksanaan KKN senantiasa disesuaikan dengan kebutuhan masyarakat serta visi dan misi STAIN Sorong.

\section{B. METODE}

Beberapa strategi yang ditempuh dalam program kegiatan $\mathrm{KKN}$ ini adalah sebagai berikut:

1. Menemui Aparat Kampung Dabatan

2. Melakukan Diskusi dengan Aparat Kampung Dabatan

3. Melakukan observasi ke sekolah guna melaksanaan kegiatan pembelajaran

4. Melakukan observasi di lingkungan masyarakat tentang kegiatan keagamaan.

5. Melakukan sosialisasi program kerja dalam hal ini adalah kegiatan seminar.

6. Pelaksanaan program kerja lainnya yang bersifat fisik dan non-fisik sesuai dengan jadwal yang telah ditetapkan. 


\section{TUJUAN KEGIATAN}

KKN merupakan program intrakurikuler, dengan tujuan utama untuk memberikan pendidikan kepada mahasiswa. Namun demikian, karena pelaksanaannya mengambil lokasi di masyarakat dan memerlukan keterlibatan masyarakat, maka realisasinya di lapangan sekaligus dapat memberikan manfaat bagi masyarakat. Oleh karena itu, tujuan dari pelaksanaan KKN memiliki arah ganda, yaitu: (1) memberikan pendidikan pelengkap kepada mahasiswa, (2) membantu masyarakat melancarkan pembangunan di wilayah masing-masing. Dengan demikian, melalui KKN akan terlihat bahwa perguruan tinggi bukan merupakan suatu kelembagaan yang terpisah dari masyarakat. Akan terjadi keterkaitan dan ketergantungan baik secara fisik dan emosional antara Perguruan Tinggi dan masyarakat, sehingga pada gilirannya akan terasa bahwa peranan perguruan tinggi sebagai pusat pengembangan IPTEK menjadi lebih nyata.

\section{Tujuan Umum}

a. Mahasiswa mampu memahami permasalahan yang ada di masyarakat dan belajar memecahkannya secara interdisipliner.

b. Menjembatani dan mendekatkan perguruan tinggi dengan masyarakat

c. Membantu pemerintah dalam upaya pemberdayaan masyarakat

d. Mengembangkan kerjasama antar disiplin ilmu dan lembaga pemerintah

2. Tujuan Khusus

Tujuan yang ingin dicapai melalui program KKN, ialah:

a. Memberikan pengalaman belajar tentang pengembangan masyarakat dan pengalaman kerja nyata pembangunan.

b. Menjadikan lebih dewasanya kepribadian mahasiswa dan bertambah luasnya wawasan mahasiswa.

c. Memacu pengembangan masyarakat dengan menumbuhkan motivasi kekuatan sendiri.

d. Mendekatkan perguruan tinggi dengan masyarakat. 


\section{SASARAN KEGIATAN}

Kegiatan KKN yang dilaksanakan selama kurang-lebih dua bulan, terhitung sejak tanggal 12 Februari sampai 12 April 2020, mempunyai tiga kelompok sasaran yaitu mahasiswa peserta KKN, masyarakat bersama lembaga pemerintah dan swasta yang dalam hal ini yaitu masyarakat beserta lembaga pemerintah dan swasta yang berada di Kampung Dabatan Distrik Misool Selatan. Selanjutnya, sasaran ketiga, STAIN Sorong selaku perguruan tinggi yang melaksankan kegiatan $\mathrm{KKN}$ ini.

1. Mahasiswa

Mahasiswa memiliki peran yang sangat penting yaitu berupaya memperkenalkan diri kepada masyarakat dan disisi lain mahasiswa harus mampu beradaptasi dengan pola kehidupan di masyarakat.

2. Masyarakat bersama Lembaga Pemerintah dan Swasta

Masyarakat adalah sasaran utama yang bersentuhan langsung dengan mahasiswa KKN di lokasi.

3. Perguruan Tinggi

Berasal dari perguruan tinggi tentunya tidak lepas dari membawa misi yang diemban setiap mahasiswa KKN guna memperkenalkan kampus kepada masyarakat luas.

\section{E. HASIL YANG DIHARAPKAN}

Dalam pelaksanaan Program kerja KKN ini, hasil yang diharapkan antara lain:

1. STAIN Sorong sebagai satu-satunya perguruan tinggi Islam di Papua Barat dapat bekerjasama dengan pemerintahan setempat melalui perantara mahasiswa KKN STAIN Sorong, dengan begitu kedepannya ada masyarakat yang mendaftarkan anak-anaknya di STAIN Sorong dan pada saat KKN, anak-anak tersebutlah yang akan diterjunkan langsung ke daerahnya masing-masing.

2. Masyarakat mendapatkan tambahan pengetahuan dan pengalaman dari mahasiswa KKN STAIN Sorong dan dapat mengaplikasikan dalam kehidupannya sehari-hari. 
Berdasarkan hasil survei dan observasi yang dilakukan oleh mahasiswa KKN di Kampung Dabatan Distrik Misol Selatan pada tanggal 12 - 13 Februari, kami melakukan rapat internal untuk menindak lanjuti program yang tepat untuk dilaksanakan di lokasi KKN. Diantaranya adalah sebagai berikut:

1. Program Kerja Fisik

a. Melakukan Jum'at Bersih

b. Pembuatan papan Nama RT, TPA Nurul Rahmah, Masjid Nurul Rahmah, Ketua Bamuskam, kepala Desa, sekretaris, Papan selamat datang

2. Program Kerja Non-Fisik

a. Pembinaan keagamaan

1) Pembinaan TPA Nurul Rahmah

2) Pembinaan Remaja dan Sosialisasi Pendidikan

3) Pengajian Majelis Taklim

4) Perlombaan menyambut Isra’ Miraj

5) Tablik Akbar Isra' Miraj

b. Transformasi keilmuan

1) Seminar Program Kerja

2) Mengajar di SD N 23 Dabatan

3) Mengajar Mengaji di TPA Nurul Rahmah

\section{F. STRATEGI PELAKSANAAN}

Adapun strategi setiap program berikut rinciannya:

\section{Program Fisik}

a. Jumat Bersih di Kampung Dabatan

Pelaksanaan Kegiatan Jumat bersih di kampung Dabatan guna membantu masyarakat membersihkan masjid dan lingkungan kampung dabatan, sesuai hasil observasi dan diskusi dengan masyarakat kampung dabatan. Dalam kegiatan jum'at bersih ini saya selaku mahasiswa KKN bertugas menyapu halaman dan juga 
menjemur karpet masjid Nurul Rahmah bekerjasama dengan temanteman mahasiswa KKN dan masyarakat dabatan membersihkan halaman masjid dan lingkungan kampung Dabatan. Yang dimana kegiatan jum'at bersih ini dilaksanakan setiap hari jum'at pada jam 08.00-selesai.

b. Pembuatan Papan Nama TPA, Masjid Nurul Rahmah, Ketua Bamuskam, Kepala Desa, Sekretaris, Papan Selamat Datang.

Dari hasil observasi yang dilakukan, di kampung dabatan kami melihat kampung dabatan belum memiliki papan nama masjid, TPA, dan papan selamat datang. Kemudian pada saat kami berdiskusi dengan kepala kampung dabatan, bapak kepala kampung mengusulkan juga agar kami membuat papan nama ketua bamuskam, kepala desa dan sekertaris setelah itu kami mahasiswa KKN berencana untuk memfasilitasi sarana perlengkapan papan nama di Kampung Dabatan dengan cara membuat papan Nama TPA Nurul Rahmah, Masjid Nurul Rahmah, Ketua Bamuskam, kepala Desa, sekretaris, dan Papan selamat datang. Dalam pembuatan papan nama kami bagi tugas Saya dan beberapa teman saya kami dapat bagian pengecatan tiang-tiang papan nama .

c. Papan Nama RT

Pembuatan papan nama RT dikampung dabatan merupakan inisiatif dari mahasiswa KKN dikarenakan dari hasil observasi yang dilakukan di Kampung dabatan, mahasiswa melihat tiap - tiap RT di Kampung Dabatan belum memiliki papan nama RT, sehingga masyarakat yang baru datang di kampung dabatan terkadang kesulitan dalam mengetahui batasan RT di Kampung Dabatan. oleh karena itu Mahasiswa KKN berinisiatif untuk membuat papan nama RT I dan II agar Masyarakat baru mudah dalam mengenal RT setempat dan mengetahui batasan-batasan RT di kampung. Dalam pembuatan papan nama RT saya dan 3 orang teman saya mendapat bagian untuk mencetak nama RT di papan.

\section{Program Non Fisik}

a. Seminar Program Kerja 
Sebelum melaksanakan seminar program kerja , Mahasiswa KKN melakukan survey di Kampung Dabatan Distrik Misol Selatan mulai dari tanggal 12 - 13 Februari. dengan melakukan pendekatan kepada para Aparat Kampung, Ketua RT, tokoh agama, tokoh Masyarakat, Guru, warga Sekitar. Survey yang dilakukan oleh Mahasiswa KKN ini merupakan salah satu cara untuk mendapatkan sekaligus merencanakan program yang dibutuhkan oleh masyrakat itu sendiri.

Sosialisasi proram kerja yang dilaksanakan oleh KKN STAIN Sorong angkatan XIV tahun 2020 posko III Kampung Dabatan Distrik Misol selatan Kabupaten Raja Ampat dihadiri oleh Dosen Pembimbing, Kepala Kampung, Staf Distrik, Ketua Pengajian, Imam Masjid, Bamuskam, Kepala Sekolah, Guru-guru Sekolah, Ketua RT, tokoh Agama, dan tokoh masyarakat. Kegiatan dengan susunan acara sebagai berikut Pembukaan, sambutan-sambutan, Pemaparan program Kerja KKN STAIN Sorong Angkatan XIV Tahun 2020, Kesimpulan, Doa dan Penutup.

Dalam kegiatan seminar program kerja saya selaku mahasiswa KKN posko III Dabatan bertugas sebagai Pembacaan doa. Kegiatan seminar program Kerja KKN STAIN Sorong Angkatan XIV Tahun 2020, dapat berjalan dengan lancar.

b. Mengajar di SD N 23 Dabatan

Mahasiswa mengadakan diskusi dengan kepala sekolah SD N 23 Dabatan untuk dapat membantu Mengajar di SD dikarenakan kurangnya tenaga kerja atau guru dalam mengajar. Sedangkan siswa yang di ajar jumlahnya cukup banyak. Oleh karena itu Mahasiswa meminta izin kepada Kepala Sekolah SD N 23 Dabatan agar dapat membantu proses belajar mengajar di SD N 23 Dabatan yang di laksanakan mulai dari jam 07.30 - 12.00 yang bertempat di SD N 23 Dabatan

Disini saya selaku mahasiswa bertugas untuk membantu guru SD N 23 Dabatan dalam mengajar peserta didik. Saya diberikan tugas untuk mengajar di kelas $\mathrm{V}$ pada hari senin dan selasa pada mata pelajaran Agama dan mata pelajaran mulok. 
c. Pembinaan TPA Nurul Rahmah

Berdasarkan survey yang di lakukan mahasiswa KKN posko II Kampung Dabatan terdapat permasalahan diantaranya kurangnya guru mengaji dengan banyaknya peserta mengaji TPA Nurul Rahmah, oleh karenanya Mahasiswa KKN posko III berinisiatif untuk membantu dalam mengajar mengaji di TPA Nurul Rahmah tersebut.

Tugas saya dalam proker pembinaan TPA Nurul Rahmah ini adalah sebagai pengajar mengaji, di TPA ini saya tidak hanya mengajarkan mereka mengaji saja, tetapi juga saya mengajarkan mereka untuk hafalan surah-surah pendek. Di akhir kegiatan pembelajaran mengaji ini saya selalu memberikan mereka motivasi dan mengajak mereka bernyanyi lagu-lagu Islam.

Selain itu saya juga meluangkan waktu saya untuk melatih adik-adik yang akan mengikuti lomba dalam rangka penyambutan Isra’Miraj. Saya melatih adik-adik menghafal surah-surah pendek. Motivasi-motivasi selalu saya berikan untuk mereka agar mereka lebih semangat lagi berlatih untuk mendapatkan juara.

d. Pengajian Majelis Taklim

Pengajian majelis taklim merupakan pengajian rutin yang dilakukan oleh ibu - ibu majelis Taklim Kampung Dabatan setiap malam jumat. Oleh karena itu ibu - ibu majelis taklim meminta kesediaan Mahasiswa KKN untuk dapat bergabung dalam kegiatan yasinan yang di laksanakan secara bergiliran di tiap - tiap rumah warga, dan pada dua minggu sekali diadakan yasinan gabungan antara kampung dabatan dan kampung yellu. Pada kegiatan pengajian majelis taklim saya bertugas sebagai peserta yang ikut serta dalam pembacaan yasinan.

e. Perlombaan menyambut Isra' Miraj

Dalam menyambut Isra' Miraj Nabi Muhammad SAW 1441 H, Mahasiswa mengadakan Lomba Adzan, Hafalan Surat-surat Pendek, Fashion Show Muslim dan puisi. Lomba ini di laksanakan di malam hari, Ba'da Isya pukul 21.00 - 23.00 yang bertempat di halaman kampung Dabatan. Dalam pelaksanakan kegiatan lomba ini, mahasiswa mengadakan kerja sama dengan Ibu-ibu Majelis Taklim, 
Remaja masjid Nurul Rahma dan Masyarakat Kampung Dabatan. Pelaksanaan lomba dalam menyambut Isra' Miraj Nabi Muhammad SAW $1441 \mathrm{H}$ berjalan dengan lancar dan meriah.

Dalam kegiatan perlombaan menyambut Isra'Miraj saya membantu panitia perlengkapan dalam mendekorasi panggung yang akan digunakan untuk lomba dan Tablik Akbar Isra' Miraj, membantu menyusun acara untuk kegiatan isra mi'raj Selain itu saya juga bertugas Membuat papan nama peserta lomba.

f. Tablik Akbar Isra' Miraj

Kegiatan tablik akbar memperingkati Isra' Miraj Nabi Muhammad SAW $1441 \mathrm{H}$, Kegiatan yang di mulai pukul 22.00 - 00.00 wit, dengan rangkaian acara, pembukaan, pembacaan kalam Ilahi, Laporan Ketua Panitia, Tausiyah, do'a dan penutup, Pada kegiatan Tablik Akbar Isra' Miraj ini Mahasiswa KKN bertindak sebagai Panitia.

Saya bertugas sebagai panitia seksi acara dalam kegiatan tablik akbar. Tugas saya adalah meyiapkan sususnan acara dan menyiapkan hadiah bersama teman-teman panitia seksi acara dan pemuda pemudi kampung dabatan.

\section{G. KESIMPULAN}

Kegiatan KKN STAIN Sorong angkatan XIV Tahun 2020 yang dilaksanakan mulai tanggal 12 Februari sampai 28 April di Kampung Dabatan Distrik Misool Selatan Kabupaten Raja Ampat ini secara keseluruhan dapat berjalan dengan baik dan lancar, meskipun terdapat beberapa kendala baik secara teknis maupun non-teknis namun semuanya itu dapat di selesaikan dan dilalui dengan baik berkat adanya kerjasama dari masyarakat, Aparat Kampung dan semua pihak yang membantu selama KKN berjalan.

Kegiatan KKN STAIN Sorong angkatan XIV Tahun 2020 di masyarakat memberikan manfaat yang sangat besar bagi mahasiswa. Kegiatan ini dapat di jadikan bekal bagi mahasiswa dalam mempersiapkan diri agar dapat bersosialisasi dengan lingkungan sekitar. 
Nurfadila Loji, Muhammad Satir Pembinaan Keagamaan dan Transformasi Keilmuan

\section{Seminar Program Kerja}
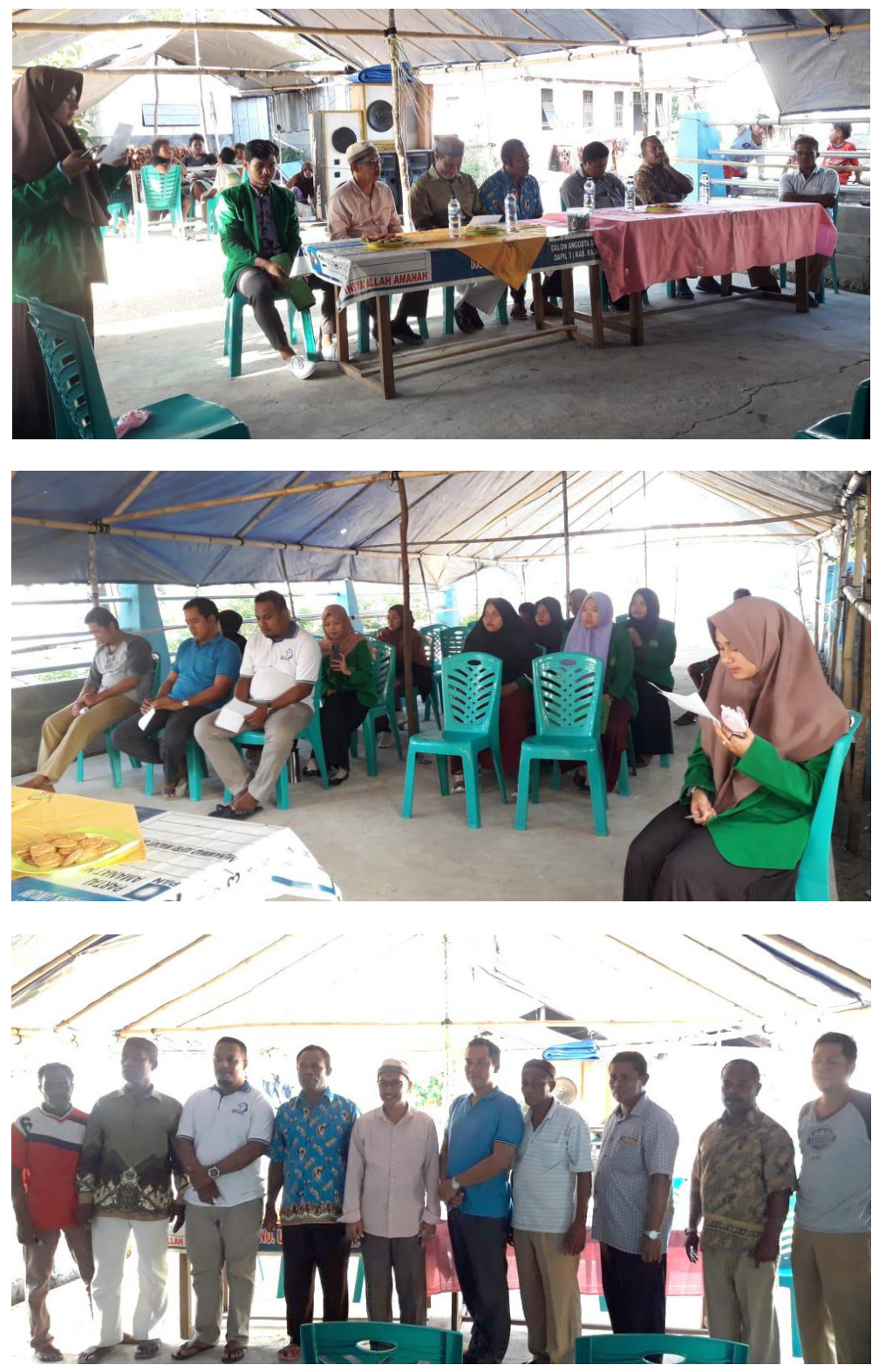
12 AL-KHIDMAH, Volume 1, Nomor 1, Mei 2021

Mengajar Mengaji di TPQ AR-ROHMAH
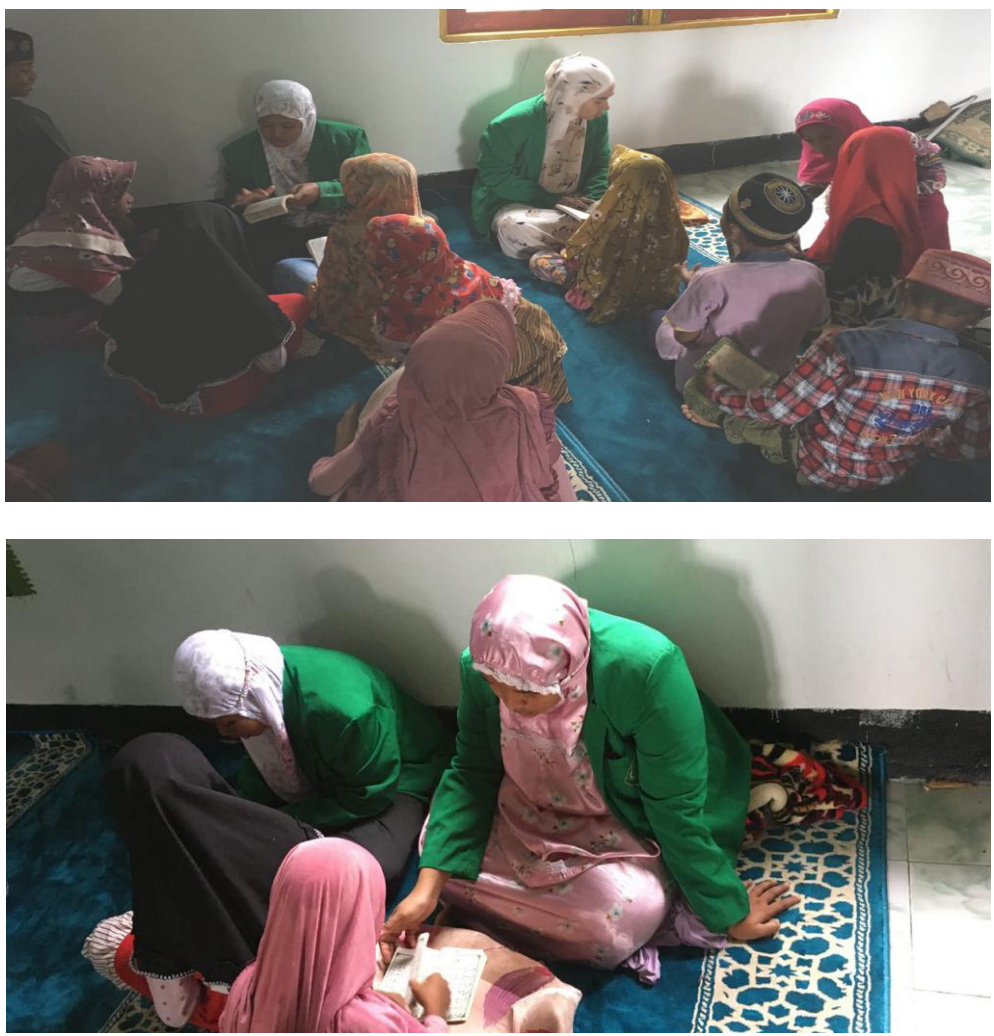

Penyerahan Hadiah dan Uang Pembinaan Kepada Pemenang Lomba

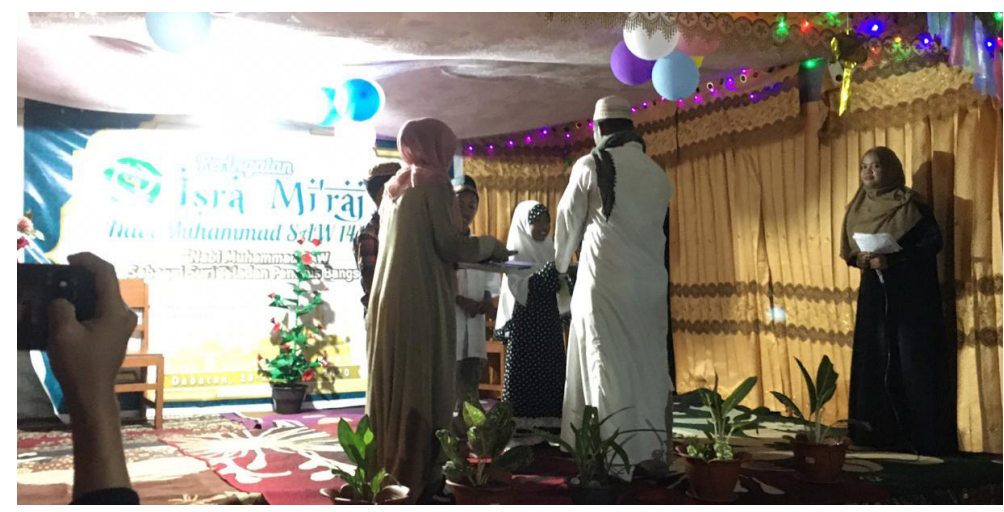


Pembentukan Remaja Masjid Ar- Rohmah
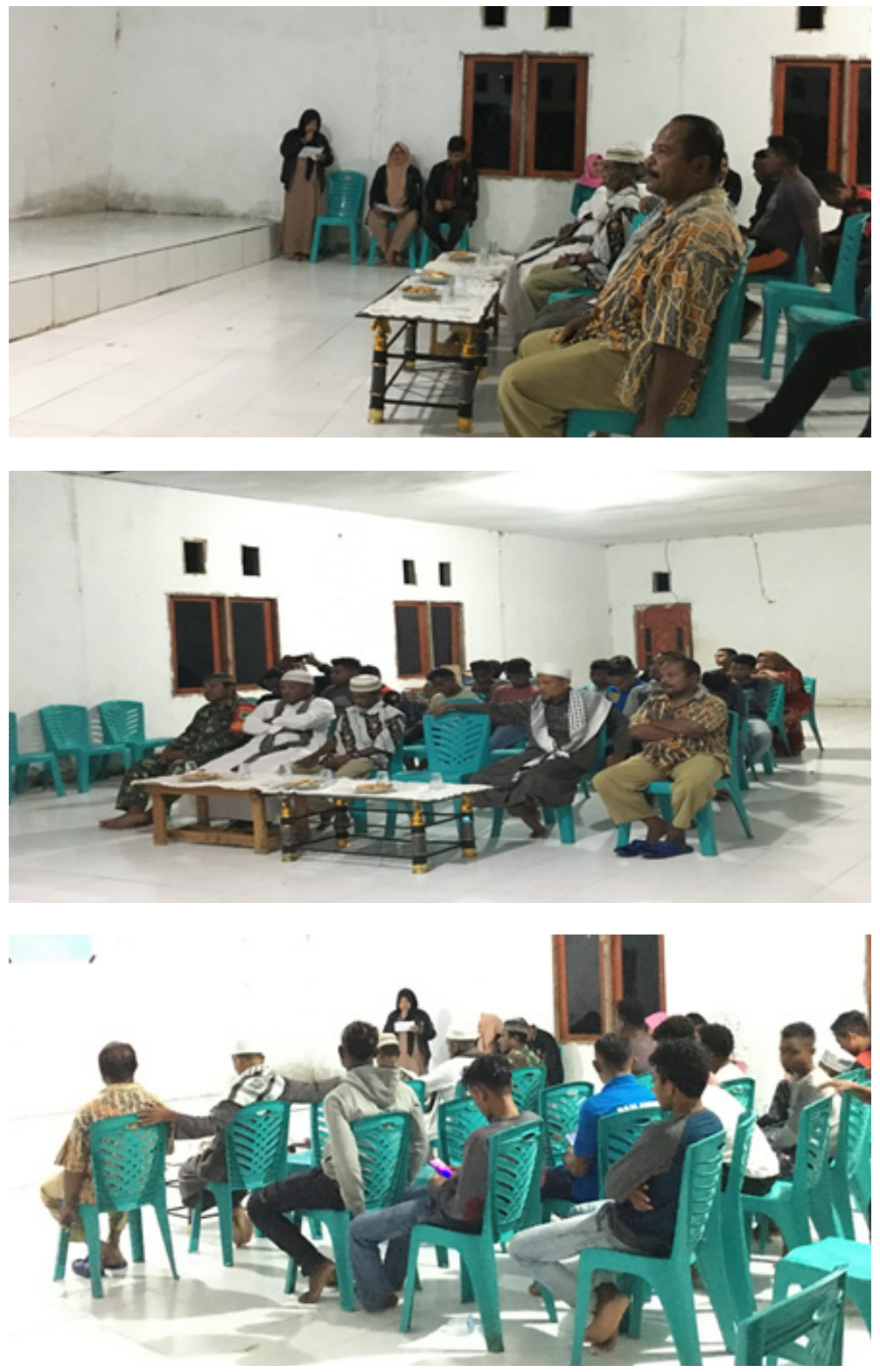
14 AL-KHIDMAH, Volume 1, Nomor 1, Mei 2021

\section{Kegiatan Jum'at Bersih}
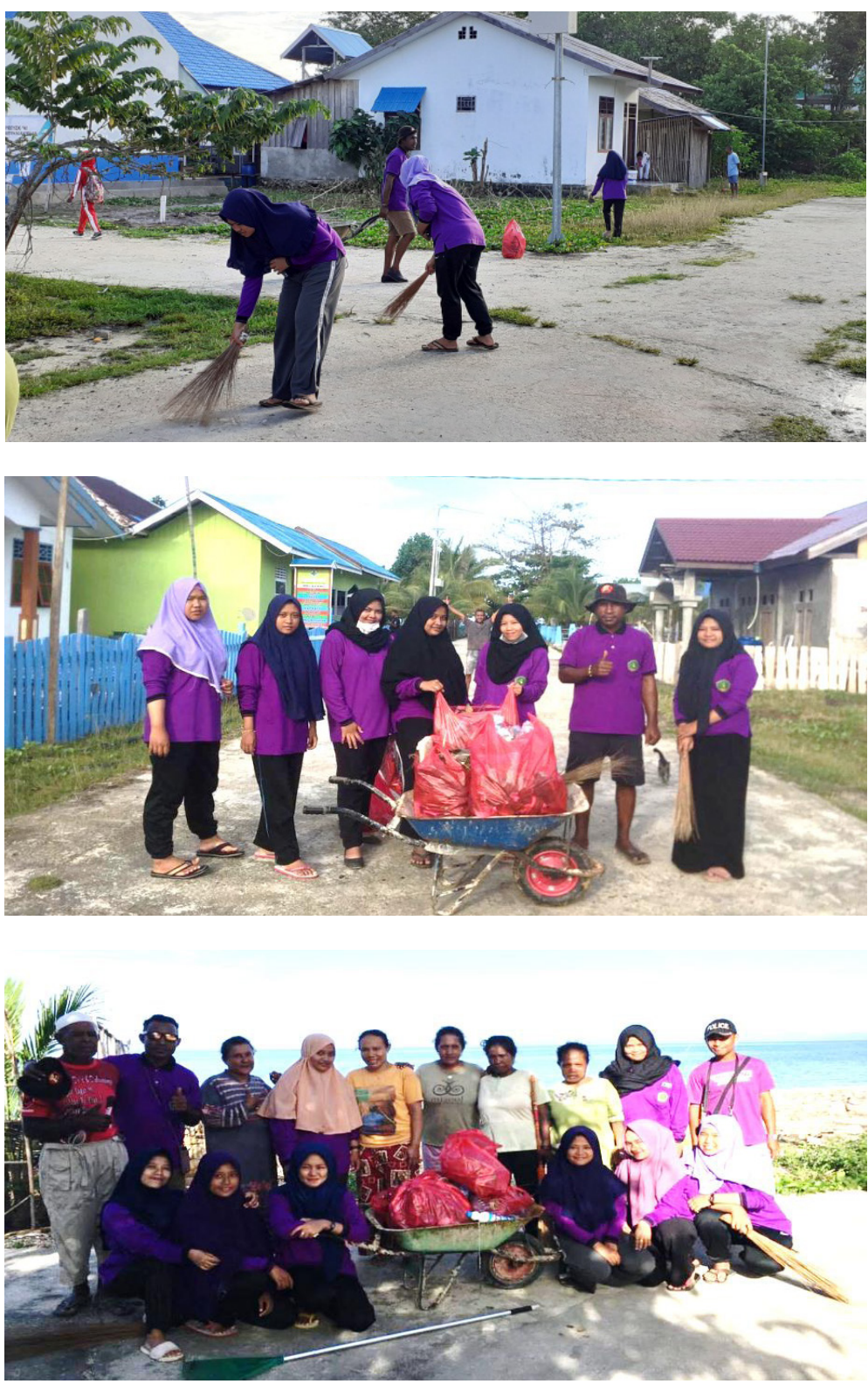
Pengajian Gabungan Ibu majelis Ta'lim di Kampung Yellu

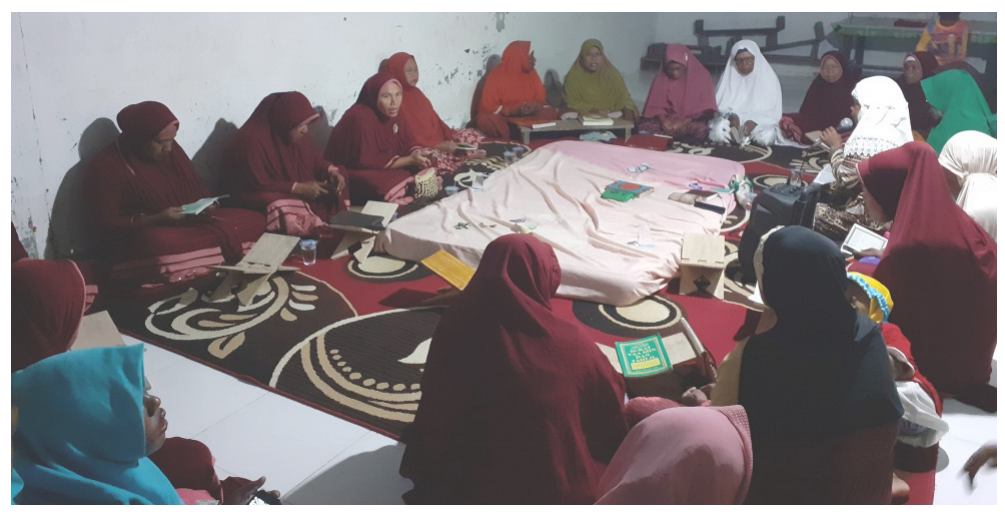

Pengajian Ibu Majelis Ta’alim Dabatan
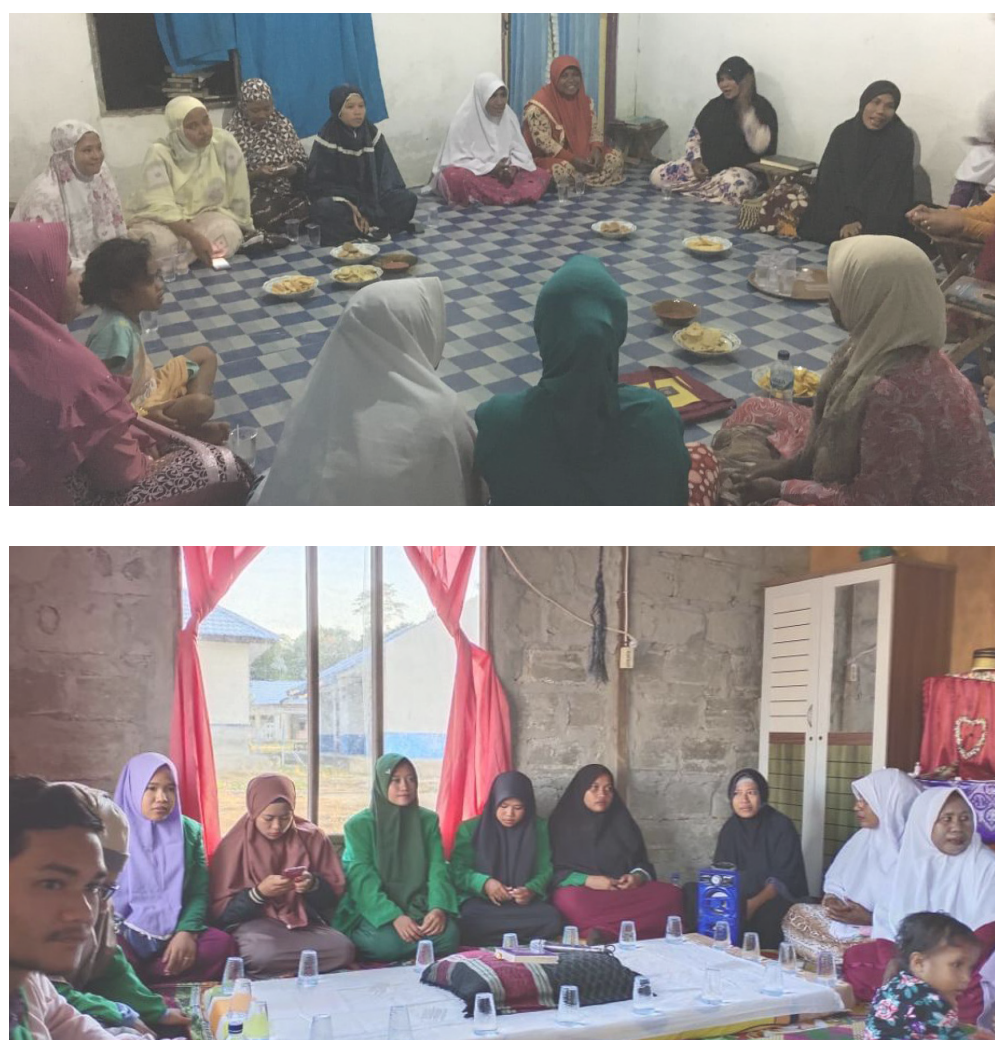
16 AL-KHIDMAH, Volume 1, Nomor 1, Mei 2021

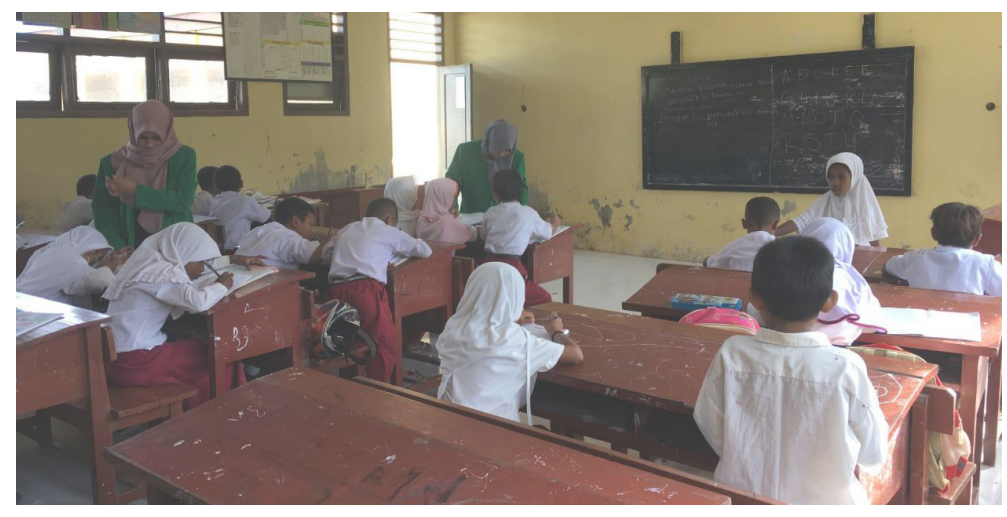

Mengajar di SD N 23 Dabatan
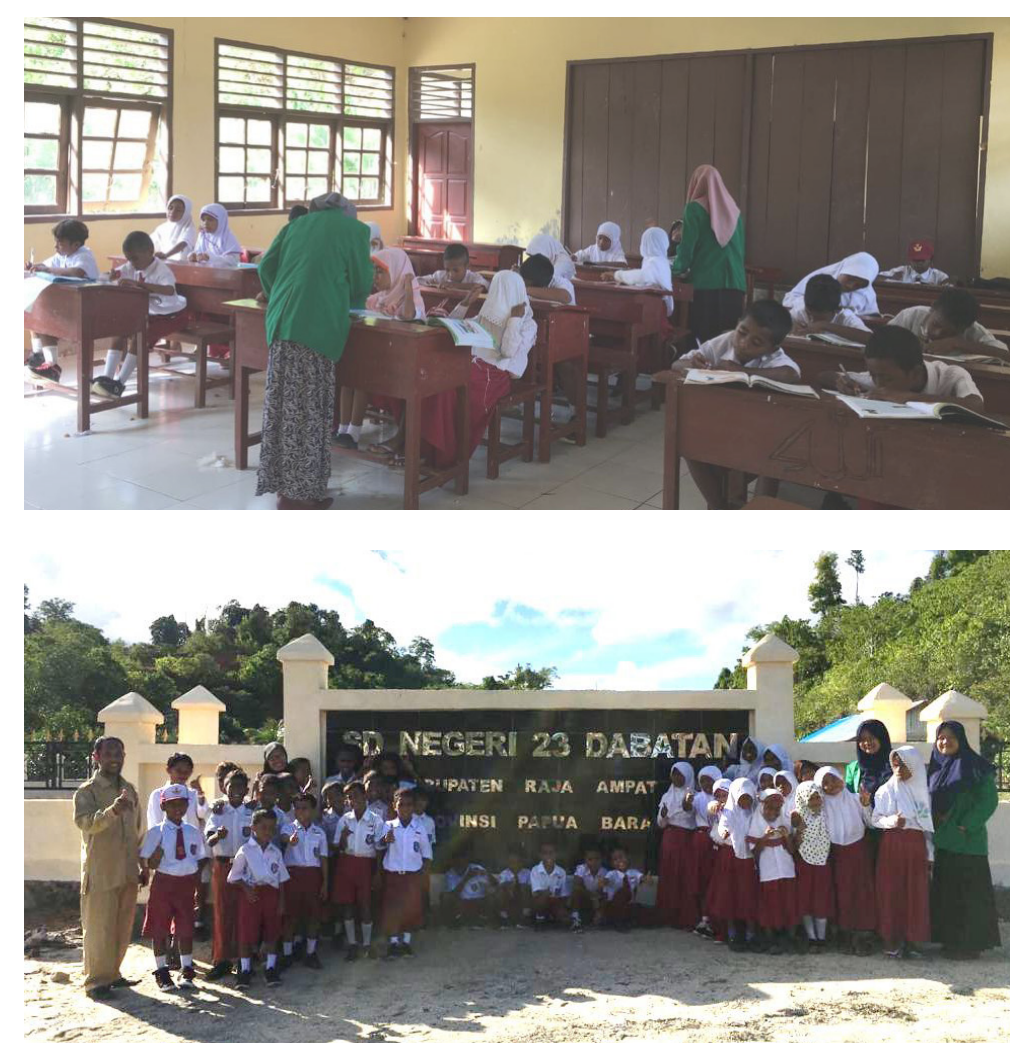
Nurfadila Loji, Muhammad Satir Pembinaan Keagamaan dan Transformasi Keilmuan

Melatih hafalan surah-surah pendek dan Azan persiapan kegiatan Isra M'iraj
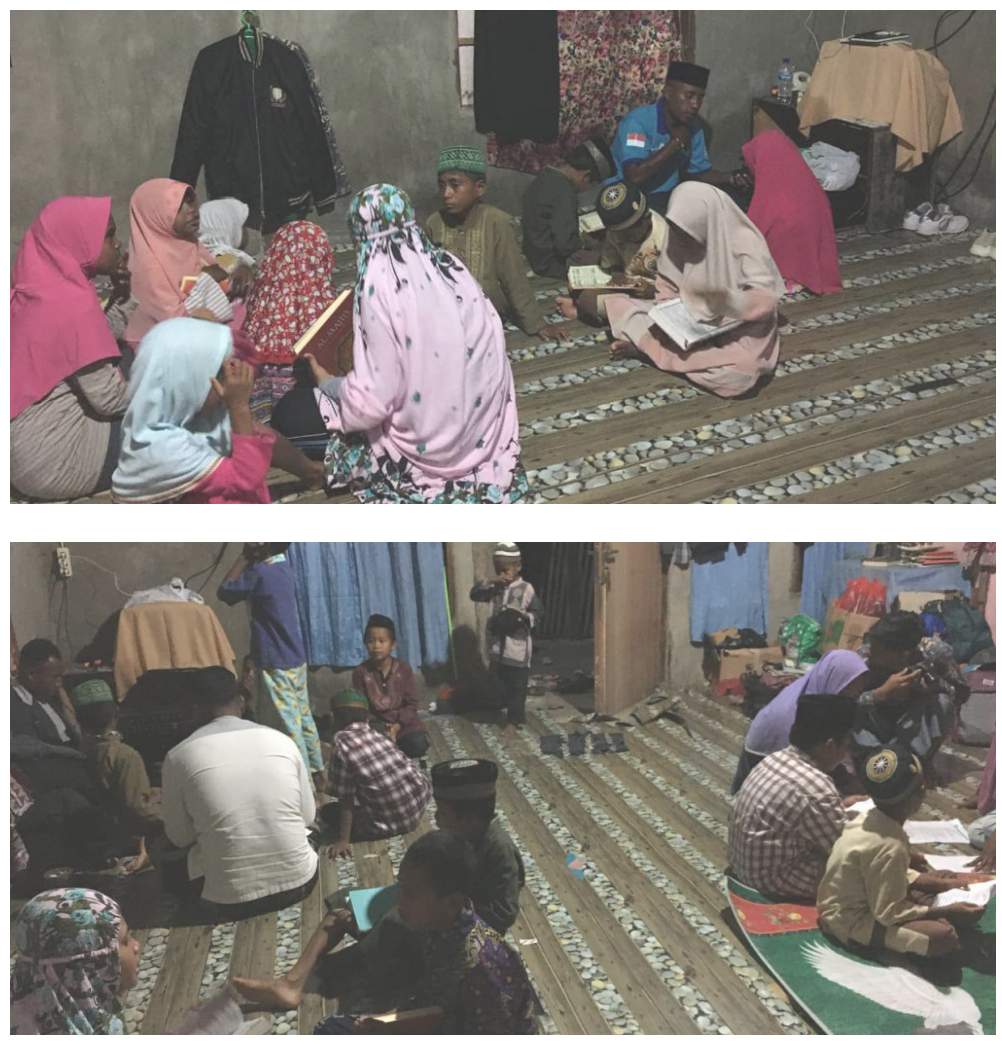

Kegiatan Isra Mi'raj

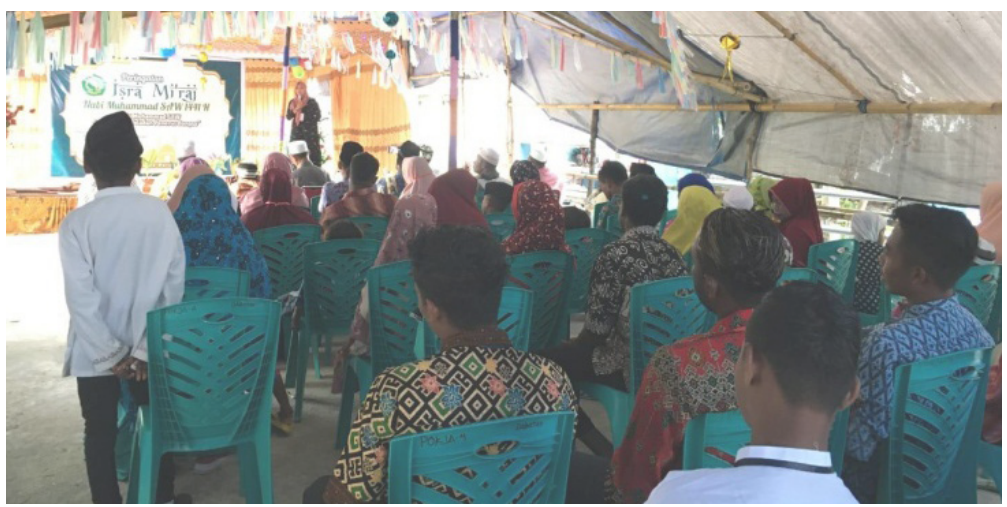


18 AL-KHIDMAH, Volume 1, Nomor 1, Mei 2021
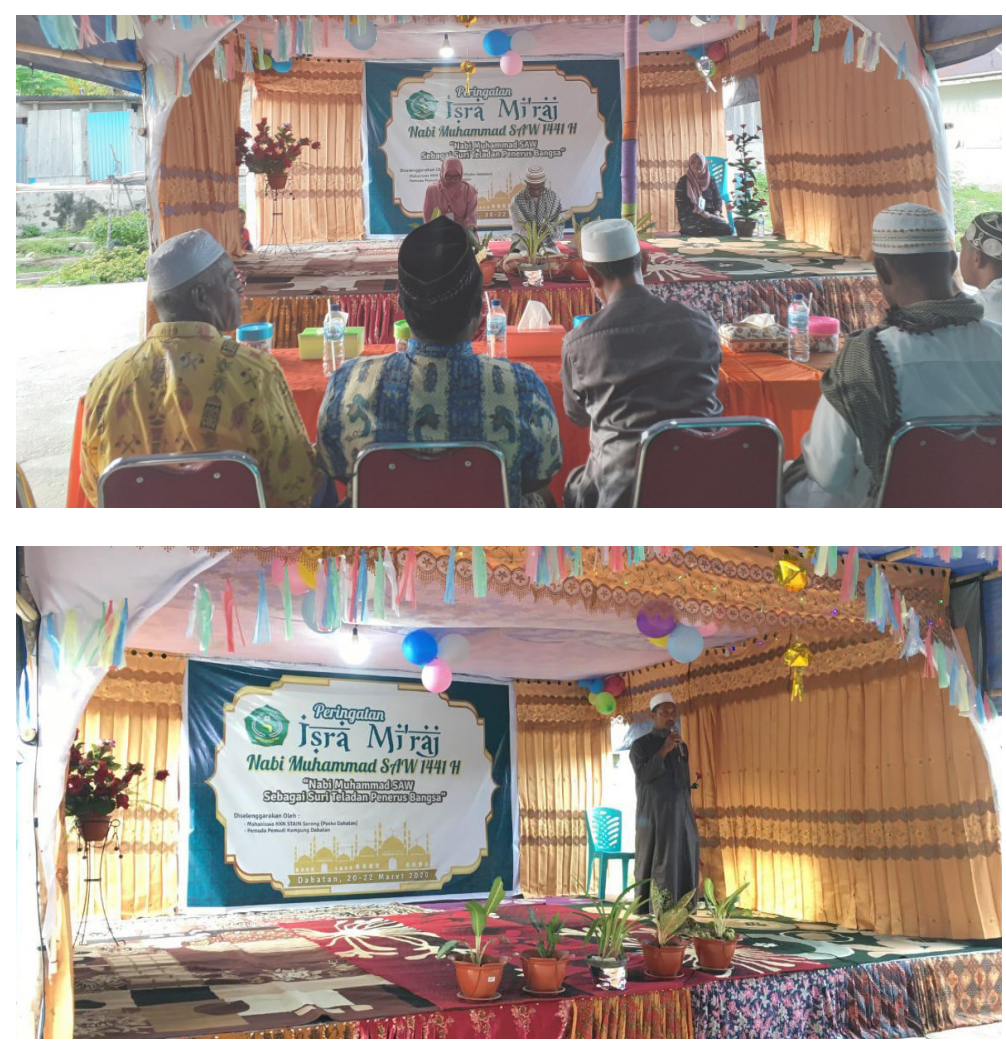

\section{Pembuatan Papan Nama}

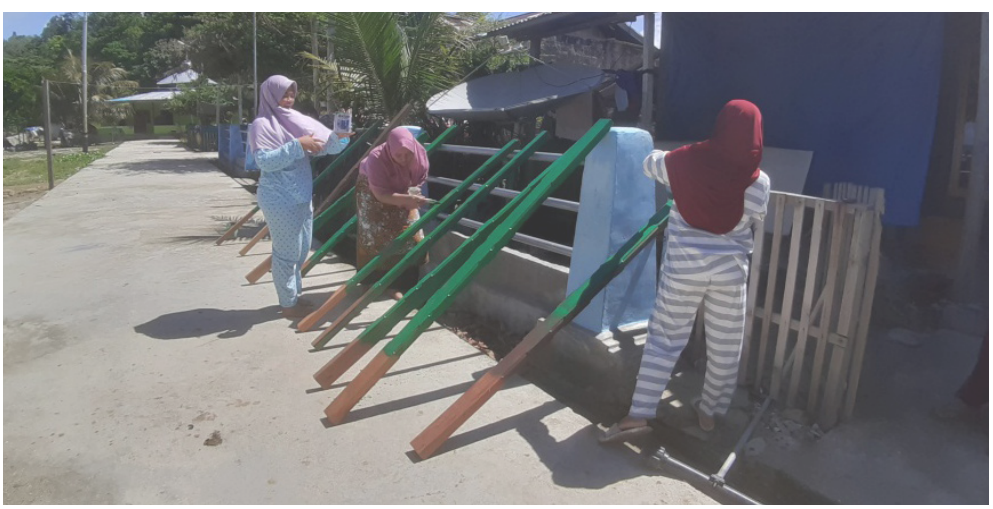


Nurfadila Loji, Muhammad Satir $\sim$ Pembinaan Keagamaan dan Transformasi Keilmuan
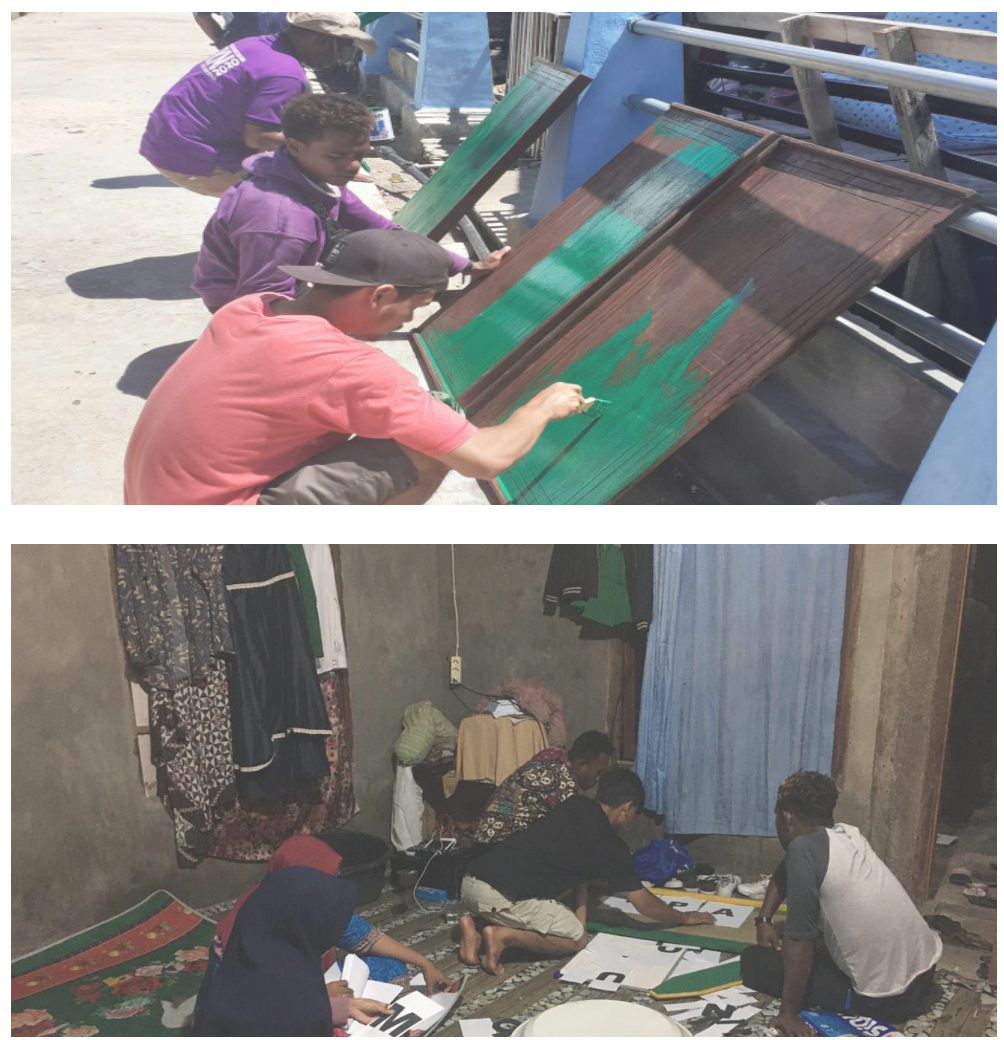

Penyerahan Mahasiswa KKN Posko III Kampung Dabatan

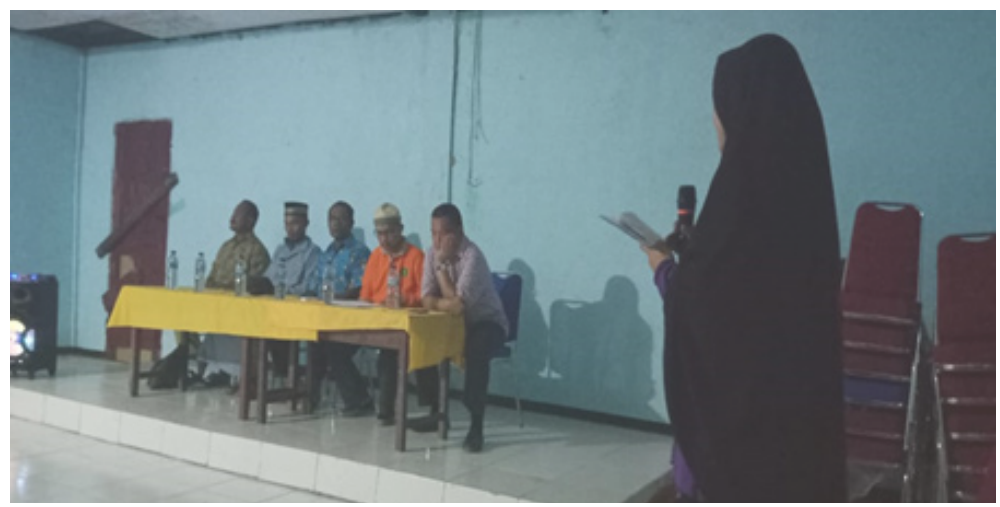



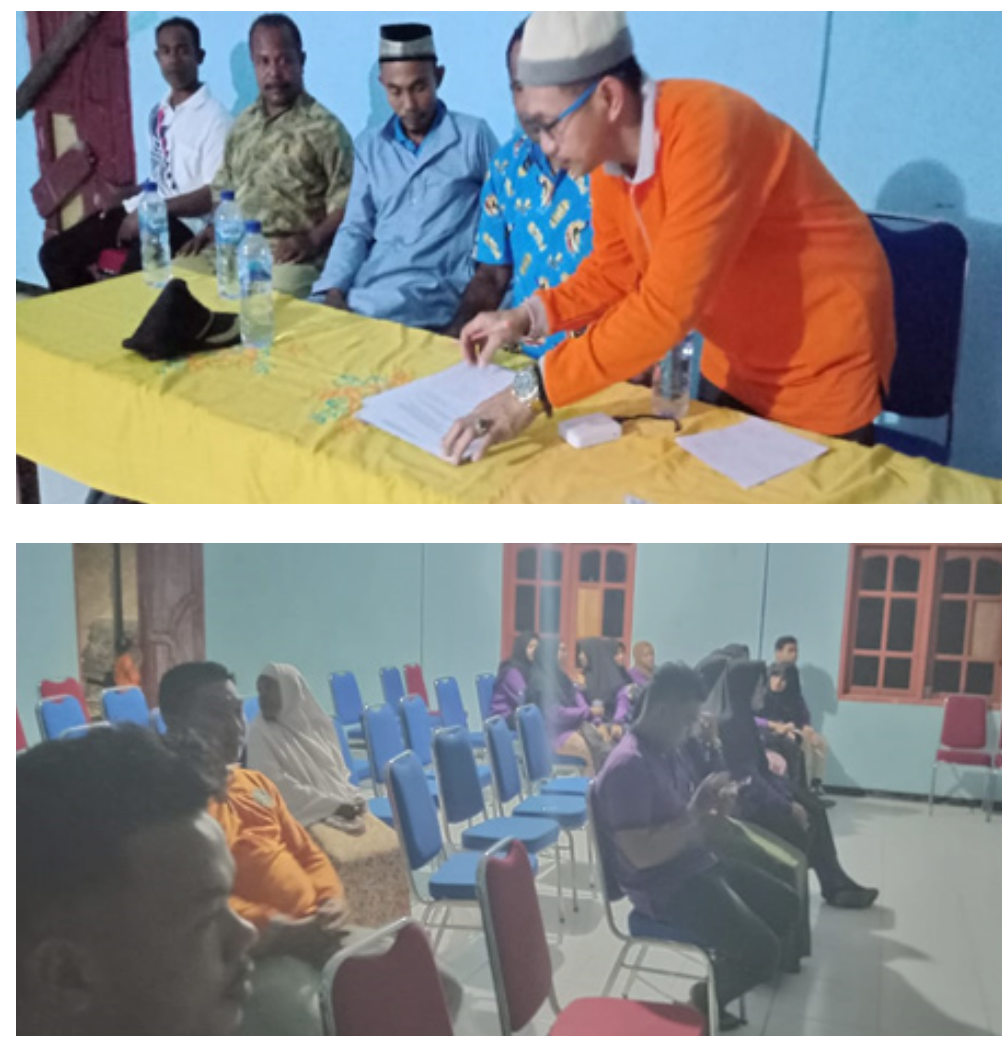

Diskusi Persiapan Kegiatan Isra Mi'raj

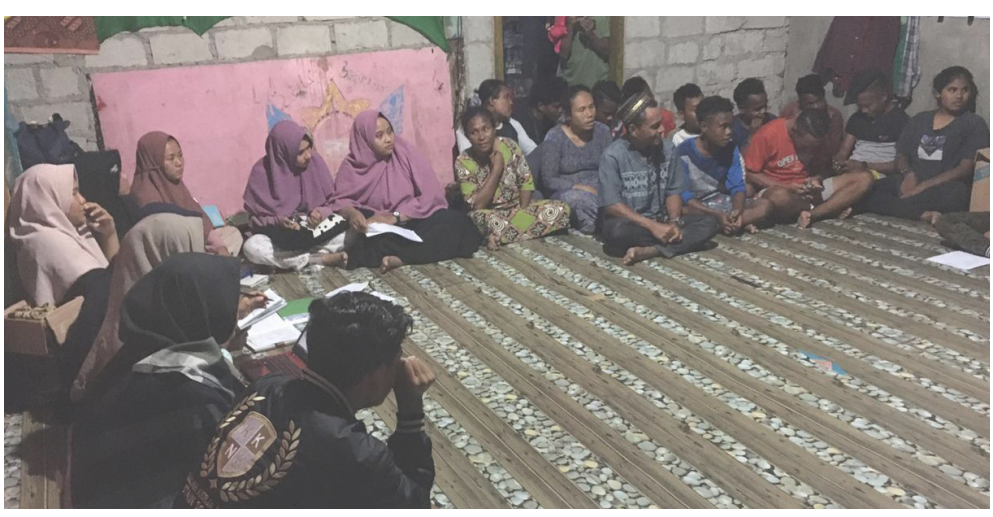




\section{Pembinaan Remaja Masjid yang diadakan di Masjid Nurul Huda Huda}

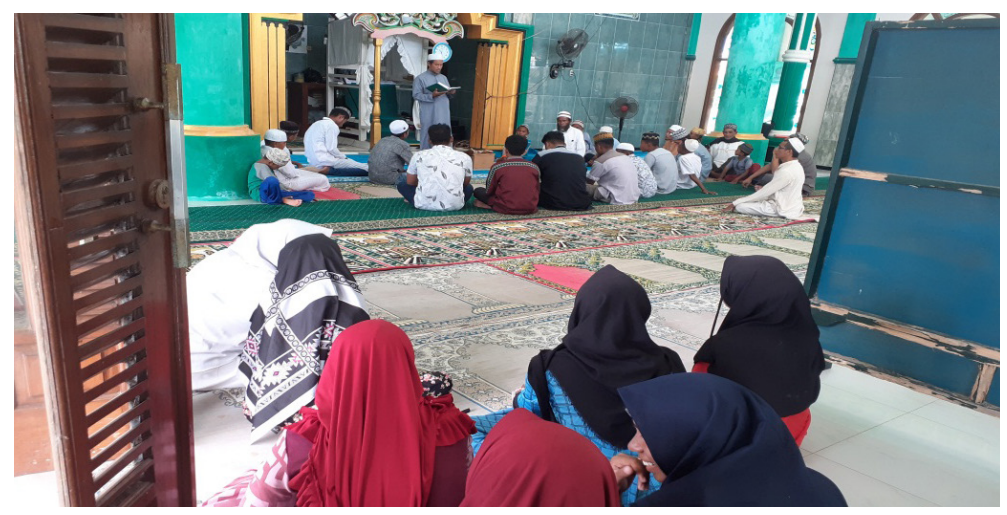

\section{Persiapan Kegiatan Isra Mi'raj}

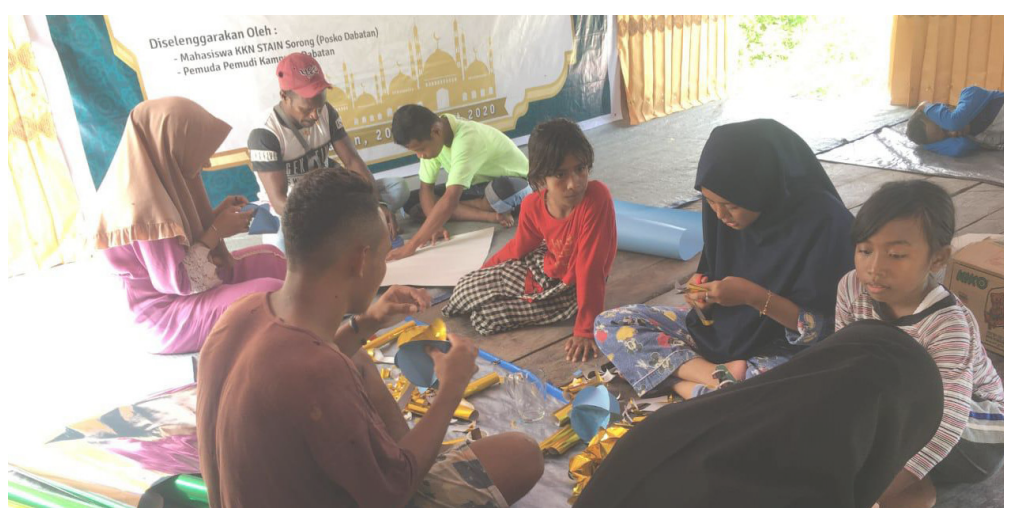


